\title{
Concomitant Presence of CD5-Positive Diffuse Large B-Cell Lymphoma and Monoclonal B Cells with the "CLL Immunophenotype" - Is It Richter's Transformation?
}

\author{
CD5-Pozitif Diffüz Büyük B-Hücreli Lenfoma ve "KLL İmmünfenotipinde" Monoklonal B \\ Hücrelerin Birlikteliği - Richter Transformasyonu mudur?
}

\author{
Sabina Langer, Jasmita Dass, Suchi Mittal, Shyam Aggarwal \\ Sir Ganga Ram Hospital, Clinic of Hematology, New Delhi, India
}

To the Editor,

The presence of diffuse large B-cell lymphoma (DLBCL) with a concomitant unsuspected population of B cells with chronic lymphoid leukemia (CLL) phenotype is very rare with no antecedent history of CLL. This may represent cases of de novo Richter's transformation or the coexistence of two neoplasms [1]. In cases where the monoclonal B-cell population does not exceed $5 \times 10^{9} / \mathrm{L}$, this may represent DLBCL with concomitant monoclonal B-cell lymphocytosis (MBL) of the CLL phenotype. The coexistence of MBL of the CLL phenotype creates a diagnostic conundrum, especially in an unusual case of CD5+ DLBCL as it may be a de novo CD5 ${ }^{+}$DLBCL or Richter transformation [2]. The former has an aggressive course compared to de novo DLBCLs $[3,4]$. CLL has been known to occur synchronously or metachronously with hairy cell leukemia [5] and DLBCL [6]. We present here a case of clinically aggressive de novo $\mathrm{CD}^{+}$ DLBCL with an unsuspected second population of CLL-like MBL detected on flow cytometry.

A 57-year-old male presented with history of fever for 3 months and the presence of mediastinal lymphadenopathy, hepatosplenomegaly, and raised serum lactate dehydrogenase levels. The complete blood count revealed hemoglobin of 9.1 $\mathrm{g} / \mathrm{dL}$, total leukocyte count of $9600 / \mu \mathrm{L}$, and platelet count of $16,000 / \mu \mathrm{L}$. A peripheral smear revealed a leukoerythroblastic blood picture with $30 \mathrm{nRBCs} / 100 \mathrm{WBCs}$, left shift, and 6\% abnormal lymphoid cells (neutrophils: $43 \%$, lymphocytes: $42 \%$, monocytes: $8 \%$, myelocytes: $3 \%$, and metamyelocytes: 4\%). The bone marrow aspirate showed 10\%-15\% abnormal lymphoid cells, which were 3-5 times the size of a small mature lymphocyte with a moderate amount of deep blue cytoplasm, round nuclei with irregularity of membranes in some, and coarsely clumped chromatin (Figure 1A).

Immunophenotyping of the bone marrow specimen revealed two distinct populations of cells: CD19+ small-sized lymphocytes (red) and CD19+ large lymphoid cells (Figure 1B). The small cells (red) showed the CLL immunophenotype with kappa light chain restriction and CD19+ large cells (blue), which also showed surface kappa restriction but were $\mathrm{CD}^{+}, \mathrm{CD} \mathrm{O}^{+}$, and $\mathrm{CD} 23$ - (Figures $1 \mathrm{C}-1 \mathrm{~F}$ ). The monoclonal B-cell count was $653 / \mu \mathrm{L}$ and hence the small cells represent MBL with the CLL phenotype. The large B cells suggested marrow infiltration by DLBCL. The bone marrow biopsy showed abnormal large lymphoid cells and interstitial infiltrate of small lymphocytes. Immunohistochemistry revealed that large cells were positive for CD20 (Figure 2A) and CD5 (Figure 2B) and negative for CD3, CD23, and CD10. The lymphoid cells were negative for cyclin D1 (Figure 2C). The Ki-67 staining of large lymphoid cells showed a high proliferative index ( $90 \%)$. The small lymphoid cells present interstitially showed positivity for CD20, CD23, and CD5 (Figures $2 \mathrm{~A}, 2 \mathrm{~B}$, and 2D). The immunohistochemical marker p53 seen in transformed CLL [6] was negative. Therefore, we concluded that there was incidentally detected MBL in this patient who otherwise had $\mathrm{CD}^{+}$DLBCL.

This patient received 2 doses of injection rituximab without any additional chemotherapy as he had hepatic dysfunction and poor ejection fraction. He had an aggressive disease course and succumbed within 10 days.

This report describes a rare situation where MBL was detected concomitantly with a CD5 ${ }^{+}$DLBCL. Gene mutation studies are necessary to differentiate these two entities. This case also calls for a consensus on reporting such cases.

Keywords: Richter's syndrome, Flow cytometry, Chronic lymphocytic leukemia, CD5-positive, Diffuse large B-cell lymphoma

Anahtar Sözcükler: Richter sendromu, Akım sitometri, Kronik lenfositik lösemi, CD5- pozitif, Diffüz büyük B-hücreli lenfoma

Conflict of Interest: The authors of this paper have no conflicts of interest, including specific financial interests, relationships, and/or affiliations relevant to the subject matter or materials included. 


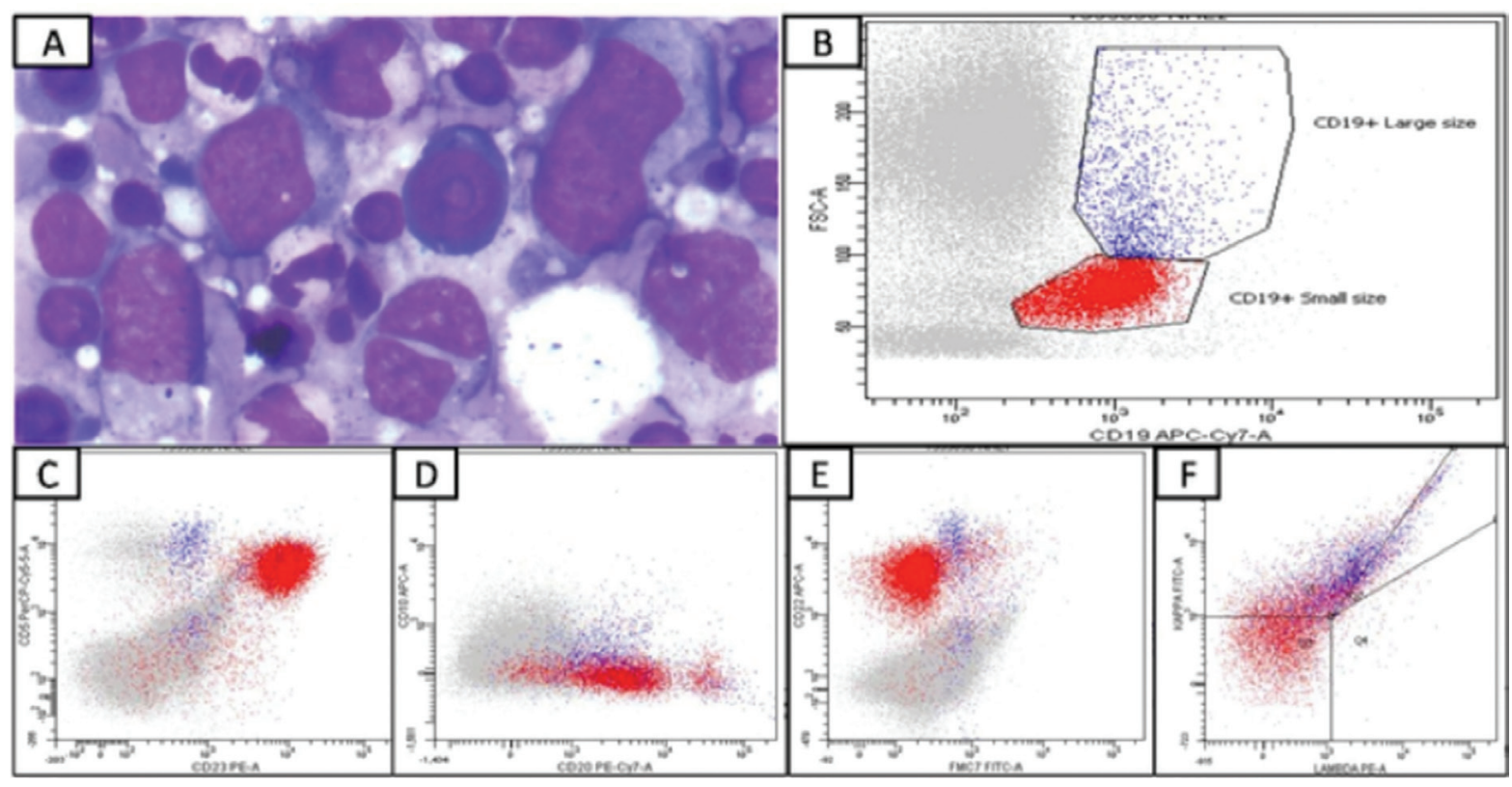

Figure 1. A) Bone marrow aspirate with 10\%-15\% abnormal lymphoid cells (3-5 times the size of a small mature lymphocyte with moderate amount of deep blue cytoplasm, round nuclei with irregularity of membranes in some, and coarsely clumped chromatin (Wright-Giemsa, 1000×). B) Flow cytometric immunophenotyping of the bone marrow specimen gated on CD19 vs. forward scatter. The small B-lymphoid cells are in red while the large B-lymphoid cells are blue. C) CD5 vs. CD23 plot: the small B-lymphoid cells (red) show a coexpression of CD5 and CD23 while the large lymphoid cells (blue) are positive for CD5 at a higher intensity than small lymphoid cells and are negative for CD23. D) CD10 vs. CD20 plot: the small B-lymphoid cells (red) show dim CD20 and are negative for CD10. Large lymphoid cells (blue) are dimly positive for CD20 and show CD10 coexpression. E) CD22 vs. FMC7 plot: the small B-lymphoid cells (red) show dim CD22 and are negative for FMC7. Large lymphoid cells (blue) are positive for CD22 at a higher intensity than small lymphoid cells and are dimly positive for FMC7. F) Kappa vs. lambda plot: both the small lymphoid cells and large lymphoid cells show kappa light chain restriction.

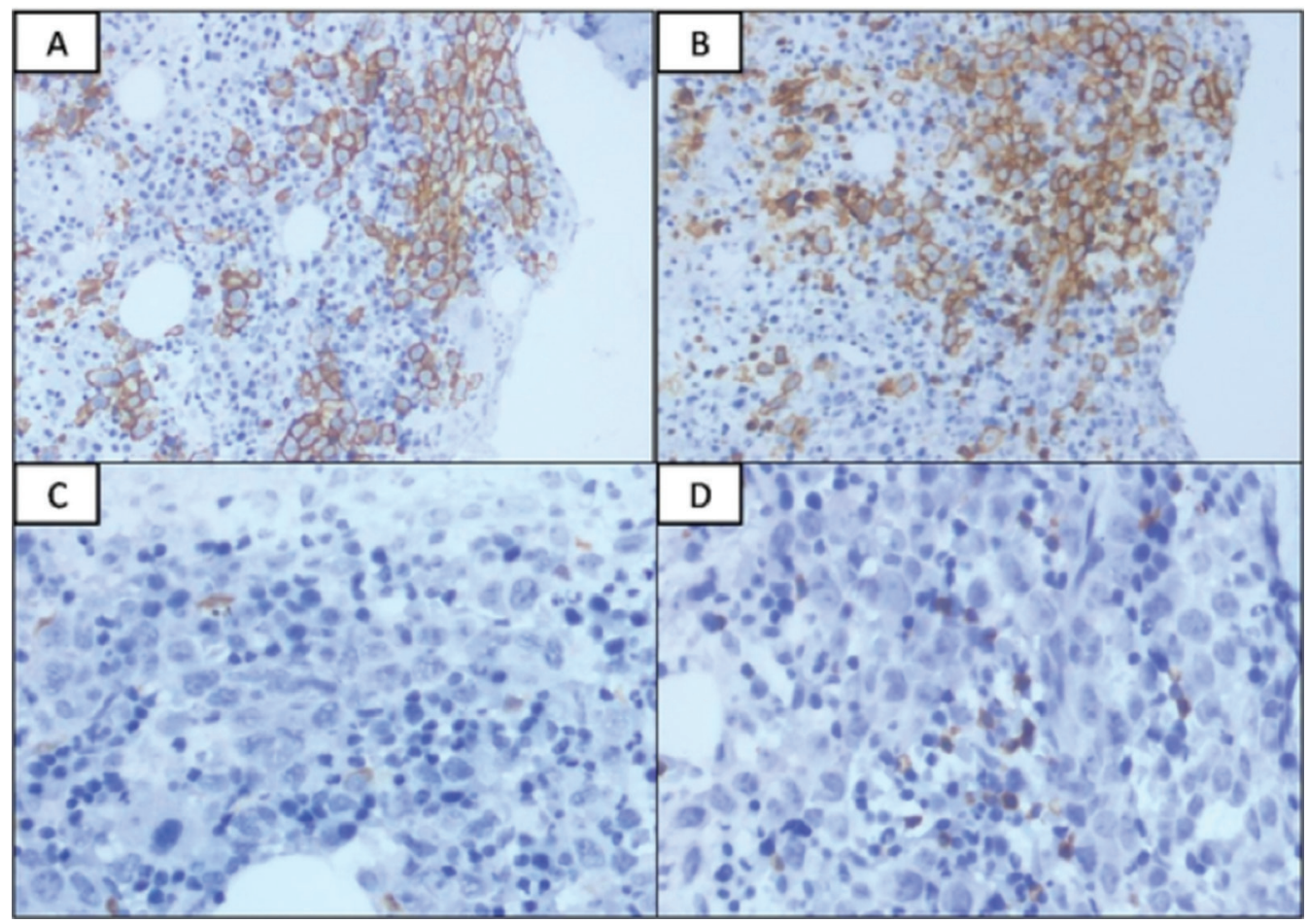

Figure 2. CD20 immunostaining highlights the large B cells and some small lymphoid cells are also positive (200x). B) Both large and small lymphoid cells show CD5 expression (200). C) Cyclin D1 is negative in both small and large lymphoid cells (400). D) The small lymphoid cells present interstitially are positive for CD23 $\left(400^{x}\right)$. 


\section{References}

1. Parikh $S A$, Rabe KG, Call TG, Zent CS, Habermann TM, Ding $W$, Leis JF, Schwager SM, Hanson CA, Macon WR, Kay NE, Slager SL, Shanafelt TD. Diffuse large B-cell lymphoma (Richter syndrome) in patients with chronic lymphocytic leukaemia (CLL): a cohort study of newly diagnosed patients. Br J Haematol 2013;162:774-782.

2. Kroft SH, Dawson DB, McKenna RW. Large cell lymphoma transformation of chronic lymphocytic leukemia/small lymphocytic lymphoma. A flow cytometric analysis of seven cases. Am J Clin Pathol 2001;115:385-395.

3. Parikh SA, Kay NE, Shanafelt TD. How we treat Richter syndrome. Blood 2014:123:1647-1657.
4. Tsimberidou AM, O'Brien S, Khouri I, Giles FJ, Kantarjian HM, Champlin R, Wen S, Do KA, Smith SC, Lerner S, Freireich EJ, Keating MJ. Clinical outcomes and prognostic factors in patients with Richter's syndrome treated with chemotherapy or chemoimmunotherapy with or without stem-cell transplantation. J Clin Oncol 2006;24:2343-2351.

5. Verma V, Giri S, Bhatt VR, Amador-Ortiz A, Armitage JO. Synchronous or metachronous hairy cell leukemia and chronic lymphocytic leukemia: a case series and literature review. Front Oncol 6:270.

6. Wei Q, Sebastian S, Papavassiliou P, Rehder C, Wang E. Metachronous/ concomitant B-cell neoplasms with discordant light-chain or heavy-chain isotype restrictions: evidence of distinct B-cell neoplasms rather than clonal evolutions. Hum Pathol 2014;45:2063-2076.

\title{
Non-Leukemic Granulocytic Sarcoma Presenting with Multiple Lymphadenopathies
}

\section{Çoklu Lenfadenopati ile Ortaya Çıkan Alösemik Granülositik Sarkom}

\author{
Ayfer Gedük', Esra T. Demirsoy ${ }^{1}$, Süheyla U. Bozkurt² ${ }^{2}$ Zafer Gülbaş ${ }^{3}$, Serkan İşgören ${ }^{4}$ \\ ${ }^{1}$ Kocaeli University Faculty of Medicine, Department of Hematology, Kocaeli, Turkey \\ ${ }^{2}$ Marmara University Faculty of Medicine, Training and Research Hospital, Department of Pathology, Istanbul, Turkey \\ ${ }^{3}$ Anadolu Medical Center, Bone Marrow Transplantation Center, Kocaeli, Turkey \\ ${ }^{4}$ Kocaeli University Faculty of Medicine, Department of Nuclear Medicine, Kocaeli, Turkey
}

\section{To the Editor,}

Granulocytic sarcoma (GS) is a rare tumor with poor prognosis that is composed of primitive myeloid cells, localized in extramedullary sites. The incidence is $2.5 \%-9.1 \%$ in acute myeloid leukemia (AML) patients and it may also occur in association with a myeloproliferative neoplasm or myelodysplastic disorders. The most common locations are the skin, lymph nodes, gastrointestinal tract, bones, and soft tissues [1].

A 68-year-old man presented with the complaint of bilateral inguinal swelling. On physical examination bilateral cervical, axillary, and inguinal multiple lymphadenopathies (LAP), approximately 2-3 cm in diameter, were noted. Initial workup revealed normal liver and renal functions; negative viral serology for epstein-barr virus, cytomegalovirus, HIV, and hepatitis $B / C$;

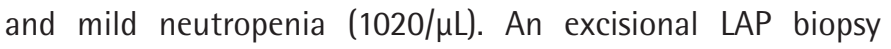
revealed disruption of the normal lymph nodal architecture by a diffuse monomorphic infiltrate comprising medium-sized mononuclear cells with a high nuclear cytoplasmic ratio and fine chromatin pattern. In immunohistochemical study, these cells were positive for $\mathrm{CD} 34, \mathrm{CD} 43, \mathrm{CD} 117$, and myeloperoxidase and negative for Tdt, CD3, CD5, CD20, CD15, CD30, CD56, EMA and Pax-5. The Ki-67 proliferation index was $45 \%$ and EBER was negative. Leukemic infiltration could not be detected in the bone marrow examination. Cytogenetic analysis was negative for $t(9,22), t(15,17), t(8,21)$, and inv16 but positive for NPM1 and $11 \mathrm{q} 23$ rearrangement. The results confirmed the diagnosis of GS (Figures 1A-1C). A positron emission tomography/ computed tomography (PET/CT) scan showed multiple hypermetabolic lymph nodes $\left(\mathrm{SUV}_{\max }: 11.8\right)$ in bilateral cervical, axillary, paracardiac, and both common iliac areas (Figure 1D). Cytosine-arabinoside plus idarubicin ( $3+7$ regimen) was started. PET/CT was repeated after chemotherapy and revealed partial response (Figure 1E). The persistent disease was confirmed by an excisional LAP biopsy and a fludarabine, cytarabine, G-CSF and idarubicin regimen was started. Since complete metabolic response was detected in the follow-up PET/CT, he underwent a matched related donor reduced-intensity conditioning hematopoietic stem cell transplantation (HSCT) (Figure 1F). He engrafted successfully and has had no recurrent GS for 8 months since the transplant.

Although it is well recognized that GS can cause localized lymphadenopathy, manifestation as bilateral multiple LAP is 